\title{
A comparative study of guided vs. pure self- treatment for premature ejaculation
}

\section{Philippe Kempeneers, Robert Andrianne, Marion Cuddy, Isabelle Georis, Quentin Longrée \& Sylvie Blairy}

To cite this article: Philippe Kempeneers, Robert Andrianne, Marion Cuddy, Isabelle Georis, Quentin Longrée \& Sylvie Blairy (2018) A comparative study of guided vs. pure selftreatment for premature ejaculation, Sexual and Relationship Therapy, 33:3, 309-324, DOI: 10.1080/14681994.2017.1323074

To link to this article: https://doi.org/10.1080/14681994.2017.1323074

曲 Published online: 04 May 2017.

Submit your article to this journal $\pi$

Џ Article views: 35

View Crossmark data 5

Citing articles: 1 View citing articles 


\title{
A comparative study of guided vs. pure self-treatment for premature ejaculation
}

\author{
Philippe Kempeneers ${ }^{a, b, c}$, Robert Andrianne ${ }^{a, c}$, Marion Cuddy ${ }^{d}$, Isabelle Georis ${ }^{c}$, \\ Quentin Longrée $^{\mathrm{a}, \mathrm{c}}$ and Sylvie Blairy ${ }^{\mathrm{a}}$

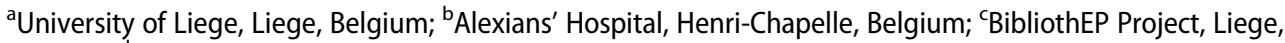 \\ Belgium; 'Maudsley Hospital, London, United Kingdom
}

\begin{abstract}
Self-treatments have previously shown some efficacy in treating premature ejaculation ( $\mathrm{PE}$ ). It has been hypothesized that adding professional support to cognitive-behaviour bibliotherapy could improve self-treatment outcomes. Therefore, the aim of this study was to compare treatment outcomes for participants with PE who used bibliotherapy alone (pure self-treatment) versus those who used the bibliotherapy with brief support from a health professional (guided self-treatment). Health professionals were not experienced sex therapists, but had attended a short training session in order to equip them to support the self-help process. In total, 135 men reporting difficulties with PE were recruited between February and June 2013. Seventy-one (52.59\%) completed the protocol: 37 in the pure self-treatment condition, 34 in the guided self-treatment condition. Thirty-five participants (50\%) met criteria for ISSM definition of lifelong PE, 14 (20\%) for acquired PE, and 22 (30\%) presented other forms of PE complaints. At 4-8 months posttreatment, improvements were found in both groups and in each subtype of PE on self-reported measures of sexual functioning and sexual cognitions. Univariate analyses indicated slightly greater treatment effects in the guided self-treatment group, but multivariate tests failed to identify a significant effect of therapist support. These mixed findings raise questions regarding the amount and quality of therapist input used in this study, and also about a possible ceiling effect of cognitive-behaviour therapy for PE.
\end{abstract}

\section{ARTICLE HISTORY}

Received 14 January 2016

Accepted 10 April 2017

\section{KEYWORDS}

Premature ejaculation; bibliotherapy; cognitivebehavioural therapy; guided self-help; sexual cognitions; therapeutic alliance

\section{Introduction}

A number of studies have found cognitive-behavioural therapy (CBT) to be a promising treatment for premature ejaculation (PE) (Cormio et al., 2015; De Carufel \& Trudel, 2006; Jern, 2013; Masters \& Johnson, 1970; Trudel \& Proulx, 1987), and a range of self-help materials have been developed in order to provide affordable CBT for PE (Carr \& Sutter, 2001; Kaplan, 1989; Kempeneers, Bauwens, \& Andrianne, 2015; Metz \& McCarthy, 2003; Zeiss \& Zeiss, 1978). Some of these have been evaluated: men with PE who used bibliotherapy manuals (those of Zeiss and Zeiss (1978), Carr and Sutter (2001), and 
Kempeneers et al. (2015), respectively) showed greater improvements in their symptoms compared to waiting-list controls (Trudel \& Proulx, 1987; De Sutter, Reynaert, Van Broeck, \& De Carufel, 2002; Kempeneers et al., 2012)

Their relative efficacy, low cost and accessibility suggest that bibliotherapies could be valuable first-line treatments for PE. On the other hand, not all participants report optimal improvements. Both Zeiss (1978) and Trudel and Proulx (1987) have suggested that additional support from a therapist, even minimal, could improve the effectiveness of a self-help intervention: the former showed that a bibliotherapy manual developed by Zeiss and Zeiss (1978) was effective only if accompanied by professional guidance, and the latter found lower satisfaction and higher drop-out (45.4\%) rates in men using the same bibliotherapy in a pure self-help condition compared to those who engaged in self-help with telephone support (14.2\% drop-out). Therefore, we hypothesised that support from a professional could improve the effectiveness of a more recent bibliotherapy material (Kempeneers et al., 2015). This could be useful in facilitating the self-treatment process by providing further information, and helping participants to adapt the material to their own situation.

This hypothesis is also supported by psychotherapy process literature, which suggests, that regardless of the modality of therapy, the therapeutic relationship is a significant predictor of treatment outcome (Hill \& Knox, 2009; Martin, Garske, \& Davis, 2000; Smith \& Glass, 1977; Wampold, 2001). More specifically, the therapeutic alliance appears to mediate outcome via two mechanisms: (1) an "alliance" effect, which involves the perception of the therapist as committed, empathic, and collaborative; and (2) an "allegiance" effect, which involves the perception of the therapist as believing in the intervention he/she is delivering (Wampold, 2001). These effects have been identified in psychotherapy for mood and anxiety disorders, and may also be relevant in sex therapy (Blanken et al., 2014). Obviously, a pure self-treatment intervention cannot benefit from alliance or allegiance effects, as no therapist is involved.

\section{Aims and hypotheses}

The main aim of this study was to evaluate the possible benefit of offering therapist support for the bibliotherapy developed by Kempeneers et al. $(2012,2015)$. This was done by comparing outcomes after pure self-treatment with those of self-treatment with brief guidance $(2 \times 45$ minutes maximum $)$ from a therapist. We hypothesised that the guided self-treatment condition would lead to significantly greater improvements in sexual functioning than pure self-treatment.

\section{Materials and methods}

\section{The self-help book}

The bibliotherapy used in this study was the self-help booklet described in Kempeneers et al. (2012) and now published under the title Fighting against Premature Ejaculation: A Practical Guide (in French) (Kempeneers et al., 2015). 


\section{Study therapists}

Fourteen students undertaking a course in clinical sexology at the Universities of Brussels and Leuven attended a 5-hour workshop to train them to support the bibliotherapy intervention. Their average age was 32 ( \pm 9 ) years (range 23-47 years). There were 10 females and 4 males. Seven therapists had Masters level qualifications in psychology or social work, 5 had Bachelors level qualifications in social work, nursing, or education, one was a gynaecologist and one had a $\mathrm{PhD}$ in sociology. Notice that about $90 \%$ of the appointments were carried out by female therapists, and more than $75 \%$ were carried out by therapists of less than 30 years old. Globally, therapists were thus mainly females and had little professional experience.

The training covered several areas: (1) overview of PE: physiology, definitions, prevalence, and possible causes; (2) interventions for PE, including CBT, drug therapy, and overview of the "Practical Guide to PE"; (3) the bibliotherapy approach and guidelines about the "coach" role; and (4) overview of the randomized controlled trial.

\section{Trial design and study population}

Participants ${ }^{1}$ were recruited between February and June 2013 through advertisements in Belgian French-speaking media. Men affected by PE were invited to contact the study team by telephone. During the phone call, diagnosis of PE was either confirmed $(N=150)$ or disconfirmed $(N=9)$ on the basis of DSM-IV-TR criteria (APA, 2000). Specifically, the inclusion criteria were (1) persistent or recurrent ejaculation with minimal sexual stimulation before, on, or shortly after penetration and before the person wishes it, and (2) marked distress or interpersonal difficulty as a result of this disturbance. Exclusion criteria were (1) PE clearly attributable to substance use such as opioid, antidepressant or antipsychotic withdrawal, (2) PE of organic aetiology (e.g. urinary tract infection or pelvic or medullar trauma), (3) PE secondary to erectile dysfunction. Additional exclusion criterion was being under 18 years of age. Maximum penetration of duration was not used to exclude participants, but self-reported intravaginal ejaculatory latency times (IELT) was assessed through an online baseline questionnaire, which allowed subtypes of PEs to be identified. The screening interviews were conducted by a psychology student who had been trained for this purpose, under the supervision of an experienced sex therapist.

Participants who were eligible for the study received a password, and after giving informed consent they were prompted to complete an online assessment questionnaire. Upon completion of this questionnaire $(N=135)$, participants were randomized either to guided self-treatment (bibliotherapy with therapist support, $N=67$ ) or to pure self-treatment (bibliotherapy alone condition, $N=68$ ). This was done by alternately allocating participants to guided and pure self-help groups following their order of enrolment in the study.

Participants randomized to the pure self-treatment condition received the bibliotherapy manual in pdf format. Those randomized to guided self-treatment were allocated to a therapist on the basis of their home address, and they were invited to an initial appointment. The bibliotherapy manual was given to participants at this appointment, again in pdf format, and they were offered the opportunity to schedule a second meeting in order to monitor their progress and obtain further guidance. The main functions of the 
appointments were: (1) to foster therapy alliance and allegiance effects; (2) to help participants to develop a better understanding of the intervention and its correct application; (3) to adapt the model to specific situations; and (4) to problem-solve reported difficulties.

Four months after receiving the self-help manual, all participants were invited to complete a post-treatment questionnaire. Non-responders were prompted to complete the questionnaire every 2 months up to 8 month post-treatment. The median number of days from pre-treatment assessment to post-treatment questionnaire completion was 132 . The values ranged from 126 to 420 days, with two exceptions (48 and 72 days) due to management problems. From the 135 participants included, 71 (52.59\%) completed the posttreatment assessment $-37(52.11 \%)$ in the pure self-help group and $34(47.89 \%)$ in the guided self-help group.

\section{Outcome measures}

\section{Socio-demographic and relationship information}

Data on participants' age and relationship status (one, several or no steady partner) were collected during the screening call. Educational level was assessed in the online questionnaire.

\section{Sexual functioning}

Diagnosis of PE was established during the phone call according to DSM-IV-TR (APA, 2000) criteria. Information collected about PE characteristics (lifelong/acquired; generalized/situational) and self-reported ejaculatory latency time pre-treatment enabled classification of participants' difficulties according to two different syndromes defined by expert committees of the International Society for Sexual Medicine (ISSM): ISSM Lifelong PE, defined as a lifelong and generalized PE with latency times of $\leq 1$ minute (McMahon et al., 2008; APA, 2013); and ISSM acquired PE, an acquired form of PE, either generalized or situation specific, with latency times of $\leq 3$ minutes (Serefoglu et al., 2014).

Sexual functioning was assessed through self-report scales. Variables measured were: 1) perceived intravaginal latency time, ranging from 1 (ejaculation before intromission) to 8 (ejaculation after 10 minutes penetration), 2) feeling of control upon ejaculation, ranging from 1 (no control) to 7 (total control), 3) level of PE-related distress (assessed through the question “To what extent is your PE a problem for you now?"), ranging from 1 (not a problem at all) to 7 (a very severe problem), and 4) general sexual satisfaction, ranging from 1 (very dissatisfied) to 7 (completely satisfied).

PE severity was also assessed using the premature ejaculation profile (PEP) developed by Patrick et al. (2008). It is a validated instrument consisting of four items rated on a 0-4 scale, which asks about respondents' perceived control over ejaculation (PEP control), satisfaction with sexual intercourse (PEP satisfaction), personal distress related to how soon ejaculation occurs (PEP distress), and interpersonal distress related to this condition (PEP int distress). Lower scores indicate more severe difficulties. An overall score (PEP index) indicates the global severity of PE.

\section{Sexual cognitions}

Sexual cognitions were measured at baseline and post-treatment using the French version of McCormick \& Jordan's sexual irrationality questionnaire (SIQ) (Kempeneers, 
Louwette, Mormont, \& Doudali, 2000; McCormick \& Jordan, 1986). The SIQ yields an overall summary score (SIQ) and four subscale scores. The first subscale, Control (SIQF1), evaluates the individual's need to keep sexuality, sexual reactions and desires under control; the Communication subscale (SIQ-F2), assesses communication around adapting sexual activities to partners' differences in erotic sensibility; the Fantasies subscale (SIQF3), evaluates the tendency to regard certain fantasies as unbecoming; and the fourth subscale, Frustration (SIQ-F4), assesses tolerance for sexual frustration. Higher scores indicate more dysfunctional or "irrational" beliefs about sexuality.

\section{Self-reported improvements post-treatment}

Changes in sexual functioning post-treatment were assessed using two self-report measures: (1) a self-report scale that asks respondents to rate their improvement in sexual functioning on a scale from 1 (no improvement) to 7 (very much improved), and (2) the Clinical Global Impression of Change (CGIC) developed by Guy (1976), a measure commonly used in clinical trials, which ranges from 1 (very much worse) to 7 (very much improved), with a score of 4 indicating no change.

\section{Participants' perception of the treatment}

At post-treatment, participants were asked to rate the usefulness of the intervention they had completed on a 7-point scale ranging from 1 (not useful at all) to 7 (extremely useful). Participants in the guided self-treatment group were also asked for feedback on the meeting with their therapist, by rating statements such as "It allowed to understand some topics I couldn't understand with the manual alone", "It was useful", "It allowed to adapt the treatment to my personal situation", and "It was an important motivational support", on a scale from 1 (strongly false) to 7 (strongly true).

\section{Therapeutic alliance}

The therapeutic alliance was assessed using a French adaptation of the working alliance inventory (WAI) (Corbière, Bisson, Lauzon, \& Ricard, 2006). This inventory comprises three subscales: (1) the bond subscale (WAI-bond), which measures the positive relational bond between the therapist and the client; (2) the task subscale (WAI-task), which assesses the level of agreement between the therapist and client concerning the tasks to be accomplished in therapy; and (3) the goal subscale (WAI-goal), which evaluates the degree of collaboration between therapist and client regarding the goals of therapy. A fourth score, WAI-total, reflects the global scale and simply represents the sum of all items.

\section{Statistical analysis}

Data were analysed using Statistica $\odot$ software, version 10 (StatSoft Inc).

$T$ tests were used to assess possible differences at baseline between treatment completers and non-completers, between treatment completers and normative data, between the two treatment groups and between subtypes of PE. They were also used to explore differences between baseline and post-treatment data. The statistical significance threshold was established at .05, and was reduced to .004 when Bonferroni corrections were applied. Effect sizes concerning changes from baseline to post-treatment were calculated using Cohen's $d$. 
Changes from baseline to post-treatment as a function of treatment group (pure vs. guided self-treatment) were assessed using repeated measures multivariate analyses of variances. Analyses were performed on three sets of dependent variables: (1) standard PE diagnostic criteria (self-reported IELT, feeling of control upon ejaculation, distress related to PE and sexual satisfaction), (2) the PEP indices, and (3) the sexual cognitions (SIQ) scales. Additional similar analyses were performed to assess treatment outcome as a function of PE subtype (lifelong PE, acquired PE and other PE complaints).

Finally, further mediators of treatment outcome were explored using stepwise linear regression. Global impression of change (CGIC) and subjective improvement scores were taken as dependent variables. Each of them was first cross-referenced (Pearson's correlation) with the interval of time between baseline and post-treatment assessments, sociodemographic information (age and education level), baseline measures of sexual functioning and cognitions. In the guided self-treatment group, they were also cross-referenced with therapist factors (age and gender) and therapeutic relationship data (WAI). Variables presenting significant correlation $(p<.05)$ with the indices of change were thus put into linear regression models, following a forward selection. Analyses were performed separately for pure and guided self-treatment groups.

\section{Results}

\section{Baseline sample characteristics}

\section{Socio-demographic and relationship data}

The average age of participants was 37.40 ( \pm 10.24$)$ years (range $19-75$ years). Forty-eight participants $(67.61 \%)$ had a higher educational qualification, and only one $(1.41 \%)$ had completed primary school or less. The majority $(87.32 \%, n=62)$ of respondents had a single partner, $1.41 \%(n=1)$ had several, and $9.86 \%(n=7)$ reported no steady partner.

\section{Sexual functioning}

Mean baseline scores on self-report measures of sexual functioning are presented in the first column of the Table 1 . With regard to latency times, $2.82 \%$ subjects $(n=2)$ reported ejaculation before penetration (score 1$), 21.13 \%(n=15)$ usually ejaculated within 30 seconds (score 2), 28.17\% $(n=20)$ between 30 seconds and one minute (score 3$), 25.35 \%$ ( $n$ $=18$ ) between one and two minutes (score 4$), 16.90 \%(n=12)$ between two and four minutes (score 5), 2.82\% $(n=2)$ between four and six minutes (score 6), $1.41 \%(n=1)$ between 6 and 10 minutes (score 7), and $1.41 \%(n=1)$ beyond 10 minutes (score 8$)$. The median value was 30-60 seconds (score 3 ).

One third of participants $(32.86 \%, n=23)$ met the ISSM criteria for lifelong PE (McMahon et al., 2008) and this proportion increased to half of participants $(50 \%, n=35)$ when the maximum duration of penetration was extended to $<2$ minutes. In 2013, a second experts committee convened by the ISSM agreed to use a maximum duration of penetration of 3 minutes for diagnosing acquired PE (Serefoglu et al., 2014). In this sample, the proportion of participants meeting these criteria was estimated to be between $12.86 \%$ (ejaculation within 2 minutes, $n=9$ ) and 20\% (ejaculation within 4 minutes, $n=14$ ).

Mean self-reported IELTs of $<2$ and $<4$ minutes were used to categorise PEs as lifelong or acquired, respectively. 
Table 1. Sexual functioning, sexual cognitions (SIQ) and self-reported change in all treatment completers.

\begin{tabular}{lccccccc}
\hline & Valid $n$ & Baseline $M(\mathrm{sd})$ & Post-treatment $M(\mathrm{sd})$ & $d$ & $t$ & $d f$ & $p$ \\
\hline Perceived latency time & 70 & $3.54(1.36)$ & $4.61(1.71)$ & 0.69 & 5.91 & 69 & $<.001$ \\
Feeling of control & 71 & $1.70(0.57)$ & $3.07(1.38)$ & 1.30 & 8.50 & 70 & $<.001$ \\
Distress & 71 & $5.67(1.01)$ & $4.04(1.73)$ & 1.15 & 7.42 & 70 & $<.001$ \\
Sexual satisfaction & 71 & $2.73(1.10)$ & $3.42(1.61)$ & 0.50 & 3.72 & 70 & $<.001$ \\
PEP control & 70 & $1.63(0.52)$ & $2.41(0.83)$ & 1.13 & 7.06 & 69 & $<.001$ \\
PEP satisfaction & 70 & $2.27(0.76)$ & $2.76(0.97)$ & 0.56 & 3.94 & 69 & $<.001$ \\
PEP distress & 70 & $2.16(0.67)$ & $2.96(0.92)$ & 0.99 & 6.25 & 69 & $<.001$ \\
PEP Int distress & 70 & $3.11(1.17)$ & $3.77(1.13)$ & 0.57 & 4.72 & 69 & $<.001$ \\
PEP index & 70 & $2.29(0.57)$ & $3.00(0.77)$ & 1.05 & 7.49 & 69 & $<.001$ \\
SIQ & 69 & $106.14(12.54)$ & $99.04(17.15)$ & 0.47 & 4.38 & 68 & $<.001$ \\
SIQ-F1 & 68 & $37.06(6.25)$ & $33.57(8.12)$ & 0.48 & 4.69 & 67 & $<.001$ \\
SIQ-F2 & 68 & $17.53(3.48)$ & $16.35(4.30)$ & 0.30 & 2.24 & 67 & $\mathrm{~ns}$ \\
SIQ-F3 & 68 & $11.31(3.47)$ & $10.02(3.05$ & 0.39 & 3.50 & 67 & $<.001$ \\
SIQ-F4 & 68 & $13.62(3.11)$ & $13.72(3.23)$ & 0.03 & 0.33 & 67 & $\mathrm{~ns}$ \\
Feeling of improvement & 68 & & $3.75(1.56)$ & & & & \\
CGIC & 67 & & $4.82(0.95)$ & & & & \\
\hline
\end{tabular}

$d$ : Cohen's d; $t$ : Student's $t$-test; $d f$ : degree of freedom; significance threshold: $p=.004$.

The remaining 22 cases showed a less severe problem in terms of duration of penetration. There is a lack of consensus in the literature regarding the diagnosis or at least the subtyping of PE for this group. Nevertheless, the two participants reporting mean latency times above 6 minutes could certainly be regarded as presenting what Waldinger described as a "premature-like" (Waldinger, 2007) or a "subjective" (Waldinger, 2013) form of $\mathrm{PE}$, which is a concern about duration of penetration in the context of ejaculation latency time falling within the normal range.

Concerning sexual cognitions, participants' scores on the total scale and the Fantasies sub-scale of the SIQ were higher than those of the normative sample $(t=2.39, d f=70, p$ $<.02$, and $t=2.54, d f=70, p<.02$, respectively). This suggests an increased tendency for sexual "irrationality", especially with regard to seeing certain sexual fantasies as unbecoming.

No differences were found between participants who completed treatment and those who did not on any of the measures related to demographics, PE severity and sexual cognitions.

\section{Differences between subtypes of PE}

Participants presenting lifelong and acquired forms of PE did not differ (at $p<.004$ ) in their socio-demographic characteristics or sexual functioning. The only difference found between subtypes of PE concerned mean IELTs, which were of $2.95( \pm 0.95)$ and 3.37 $( \pm 1.07)$ for lifelong and acquired PE groups, respectively (median between $30 \mathrm{sec}$ and 1 $\min )$, both different, with a $t$-value of $3.09(d f=68$; $p<.003)$, from the remaining cases group, for whom the mean IELT was 4.23 ( \pm 1.69$)$ (median between 2 and $4 \mathrm{~min}$ ).

\section{Pure versus guided self-treatment}

Participants in the guided self-treatment group scored slightly lower at baseline on the Control subscale of the SIQ than those in the pure self-treatment group $(M=34.50$, sd $=$ 6.11 vs. $M=39.33, \mathrm{sd}=5.52, t=3.26, d f=69, p<.002)$. No other differences were found. 
Table 2. Sexual functioning, sexual cognitions (SIQ) and self-reported change in the sub-sample of subjects meeting the ISSM diagnosis criteria for lifelong or acquired PE.

\begin{tabular}{lccccccc}
\hline & Valid $n$ & Baseline $M(\mathrm{sd})$ & Post-treatment $M(\mathrm{sd})$ & $d$ & $t$ & $d f$ & $p$ \\
\hline Perceived latency time & 48 & $3.19(1.07)$ & $4.52(1.78)$ & 0.91 & 5.77 & 47 & $<.001$ \\
Feeling of control & 48 & $1.63(0.57)$ & $3.13(1.42)$ & 1.39 & 7.68 & 47 & $<.001$ \\
Distress & 48 & $5.65(1.00)$ & $4.06(1.79)$ & 1.10 & 5.84 & 47 & $<.001$ \\
Sexual satisfaction & 48 & $2.54(0.92)$ & $3.31(1.64)$ & 0.58 & 3.52 & 47 & $<.001$ \\
PEP control & 48 & $1.60(0.49)$ & $2.38(0.89)$ & 1.09 & 5.62 & 47 & $<.001$ \\
PEP satisfaction & 48 & $2.15(0.74)$ & $2.65(1.00)$ & 0.57 & 3.02 & 47 & $\mathrm{~ns}$ \\
PEP distress & 48 & $2.10(0.66)$ & $2.98(0.98)$ & 1.05 & 5.40 & 47 & $<.001$ \\
PEP Int distress & 48 & $2.98(1.19)$ & $3.73(1.14)$ & 0.64 & 4.64 & 47 & $<.001$ \\
PEP index & 48 & $2.21(0.57)$ & $2.96(0.84)$ & 1.04 & 6.38 & 47 & $<.001$ \\
SIQ & 47 & $107.28(12.63)$ & $99.51(17.18)$ & 0.52 & 3.90 & 46 & $<.001$ \\
SIQ-F1 & 46 & $37.26(6.35)$ & $33.67(8.06)$ & 0.49 & 3.78 & 45 & $<.001$ \\
SIQ-F2 & 46 & $17.76(3.54)$ & $16.61(4.50)$ & 0.28 & 1.88 & 45 & $\mathrm{~ns}$ \\
SIQ-F3 & 46 & $11.63(3.36)$ & $10.35(3.16)$ & 0.39 & 2.80 & 45 & $\mathrm{~ns}$ \\
SIQ-F4 & 46 & $13.89(3.01)$ & $13.74(3.23)$ & 0.05 & 0.45 & 45 & $\mathrm{~ns}$ \\
Feeling of improvement & & & $3.63(3.80)$ & & & &
\end{tabular}

$d$ : Cohen's d; $t$ : Student's $t$-test; $d f$ : degree of freedom; significance threshold: $p=.004$.

\section{Post-treatment outcomes}

\section{Univariate analyses}

At post-treatment follow-up, all participants who completed treatment, with or without therapist guidance, reported improvements in sexual functioning and cognitions. Table 1 (all completers) and Table 2 (lifelong and acquired PE subgroup) highlight medium $(d>$ $0.5)$ to large $(d>0.8)$ effect sizes for measures of sexual functioning, and small $(d>0.2)$ to medium $(d>0.5)$ effect sizes for sexual cognitions. Effect sizes were particularly large on measures of control and distress, which are, along with duration of penetration, widely considered as the main indicators of PE. Table 3 indicates that improvements were reported both in guided and pure self-treatment groups.

Apart from the SIQ-F2, which was higher in the pure self-treatment group both at baseline and at post-treatment, no significant differences between the two groups were found at post-treatment (Table 3). However, paired sample t-tests revealed significant changes from baseline to post-treatment on more measures in the guided self-treatment group than in the pure self-treatment group.

Mean scores on the Clinical Global Impressions of Change (CGIC) were between 4 (no change) and 5 (slightly improved). Figure 1 illustrates how scores were distributed: at post-treatment assessment $55.55 \%(n=20)$ participants in the pure self-treatment group and $83.88 \%(n=26)$ of those in the guided self-treatment group reported their PE problem had at least slightly improved. Figure 2 presents the distribution of self-reported improvement in sexual functioning scores: only $13.89 \%(n=5)$ of pure self-treatment participants reported "no improvement" and 33.33\% $(n=12)$ reported "no" or "minimal improvement". This proportion was quite similar to the $35 \%$ found with the same materials in the study by Kempeneers et al. (2012). In the guided self-treatment group, only $6.25 \%(n=2)$ participants reported "no improvement" and $18.75 \%(n=6)$ reported "no" or "minimal improvement". 
Table 3. Changes from baseline to post-treatment in guided self-help and pure self-help groups (significance threshold: $p=.004$ ).

\begin{tabular}{|c|c|c|c|c|c|c|c|}
\hline & Valid $n$ & Baseline $M(s d)$ & Post-treatment $M(s d)$ & $d$ & $t$ & $d f$ & $p$ \\
\hline \multicolumn{8}{|l|}{ Guided self-help } \\
\hline$\overline{\text { Perceived latency time }}$ & 34 & $3.24(1.44)$ & $4.62(1.65)$ & 0.89 & 5.38 & 33 & $<.001$ \\
\hline Feeling of control & 34 & $1.74(0.62)$ & $3.12(1.41)$ & 1.27 & 6.19 & 33 & $<.001$ \\
\hline Distress & 34 & $5.29(1.19)$ & $3.47(1.52)$ & 1.33 & 6.41 & 33 & $<.001$ \\
\hline Sexual satisfaction & 34 & $2.76(1.21)$ & $3.74(1.66)$ & 0.67 & 3.17 & 33 & $<.004$ \\
\hline PEP control & 33 & $1.61(0.56)$ & $2.55(0.87)$ & 1.28 & 5.24 & 32 & $<.001$ \\
\hline PEP Satisfaction & 33 & $2.27(0.84)$ & $2.88(1.08)$ & 0.69 & 3.20 & 32 & $<.004$ \\
\hline PEP distress & 33 & $2.24(0.71)$ & $3.18(1.01)$ & 1.07 & 4.41 & 32 & $<.001$ \\
\hline PEP Int distress & 33 & $3.27(1.23)$ & $3.97(1.21)$ & 0.57 & 3.11 & 32 & $<.004$ \\
\hline PEP index & 33 & $2.35(0.62)$ & $3.14(0.82)$ & 1.09 & 5.23 & 32 & $<.001$ \\
\hline SIQ & 32 & $102.13(12.89)$ & $93.50(15.74)$ & 0.60 & 4.26 & 31 & $<.001$ \\
\hline SIQ-F1 & 32 & $34.50(6.11)$ & $30.44(8.35)$ & 0.53 & 3.52 & 31 & $<.002$ \\
\hline SIQ-F2 & 32 & $16.72(3.52)$ & $15.22(4.76)$ & 0.36 & 1.73 & 31 & ns \\
\hline SIQ-F3 & 32 & $10.97(3.52)$ & $9.22(3.18)$ & 0.52 & 3.31 & 31 & $<.003$ \\
\hline SIQ-F4 & 32 & $13.12(3.20)$ & $13.25(3.48)$ & 0.04 & 0.23 & 31 & ns \\
\hline Feeling of improvement & 32 & & $4.16(1.55)$ & & & & \\
\hline CGIC & 33 & & $5.03(1.02)$ & & & & \\
\hline \multicolumn{8}{|l|}{ Pure self-help } \\
\hline Perceived latency time & 36 & $3,83(1.23)$ & $4.61(1.78)$ & 0.51 & 3,12 & 35 & $<.004$ \\
\hline Feeling of control & 37 & $1.68(0.53)$ & $3.03(1.36)$ & 1.31 & 5.80 & 36 & $<.001$ \\
\hline Distress & 37 & $5.97(0.83)$ & $4.57(1.76)$ & 1.02 & 4.35 & 36 & $<.001$ \\
\hline Sexual satisfaction & 37 & $2.70(1.00)$ & $3.14(1.53)$ & 0.34 & 2.02 & 36 & ns \\
\hline PEP control & 37 & $1.65(0.48)$ & $2.30(0.78)$ & 1.00 & 4.79 & 36 & $<.001$ \\
\hline PEP Satisfaction & 37 & $2.27(0.69)$ & $2.65(0.86)$ & 0.48 & 2.34 & 36 & ns \\
\hline PEP distress & 37 & $2.08(0.64)$ & $2.76(0.80)$ & 0.94 & 4.49 & 36 & $<.001$ \\
\hline PEP Int distress & 37 & $2.97(1.12)$ & $3.54(1.04)$ & 0.53 & 3.56 & 36 & $<.002$ \\
\hline PEP index & 37 & $2.24(0.53)$ & $2.86(0.71)$ & 0.99 & 5.39 & 36 & $<.001$ \\
\hline SIQ & 37 & $109.62(11.29)$ & $103.84(17.08)$ & 0.40 & 2.34 & 36 & ns \\
\hline SIQ-F1 & 36 & $39.33(5.52)$ & $36.36(6.88)$ & 0.48 & 3.09 & 35 & $<.004$ \\
\hline SIQ-F2 & 36 & $18.25(3.32)$ & $17.36(3.63)$ & 0.26 & 1.41 & 35 & ns \\
\hline SIQ-F3 & 36 & $11.61(3.43)$ & $10.83(2.74)$ & 0.25 & 1.67 & 35 & ns \\
\hline SIQ-F4 & 36 & $14.06(2.99)$ & $14.14(2.98)$ & 0.03 & 0.23 & 35 & ns \\
\hline Feeling of improvement & 36 & & $3.39(1.50)$ & & & & \\
\hline CGIC & 36 & & $4.64(0.87)$ & & & & \\
\hline
\end{tabular}

$d$ : Cohen's d; t: Student's $t$-test; $d f$ : degree of freedom.

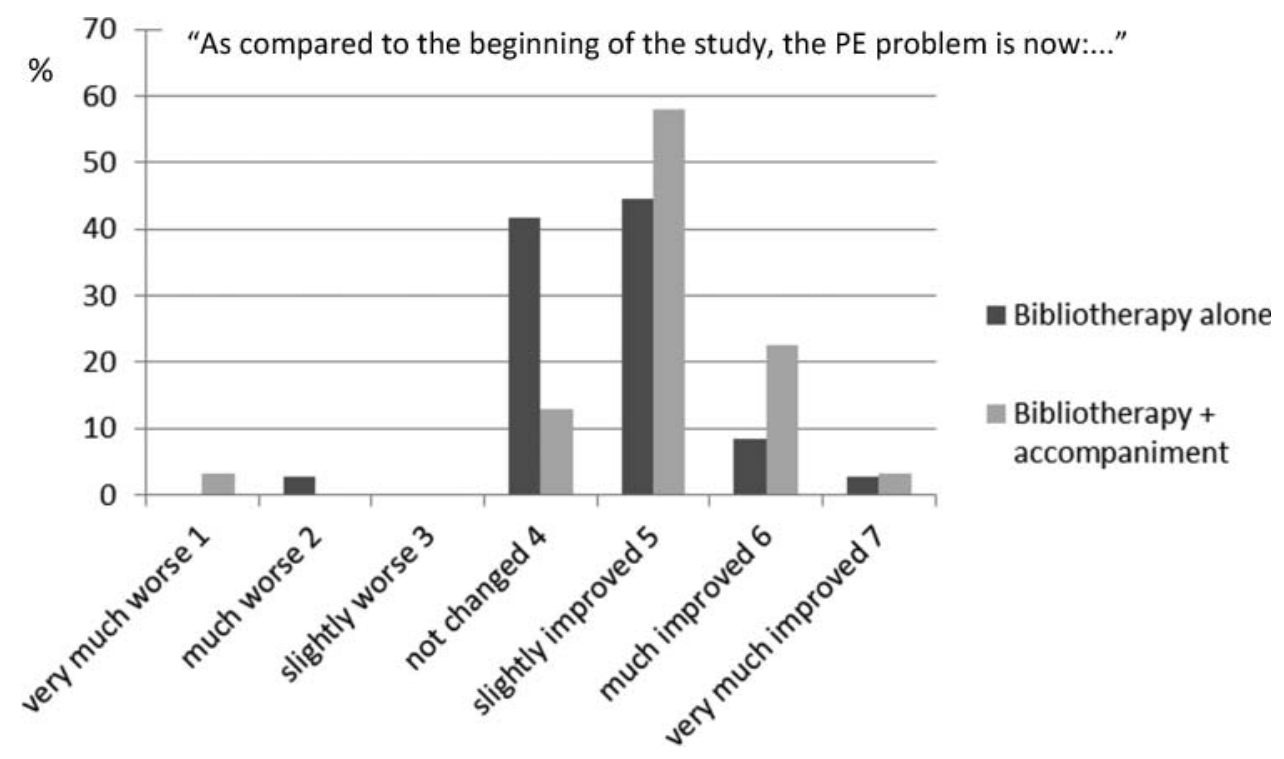

Figure 1. Clinical global impression of change scores in pure self-treatment and guided self-treatment groups. 


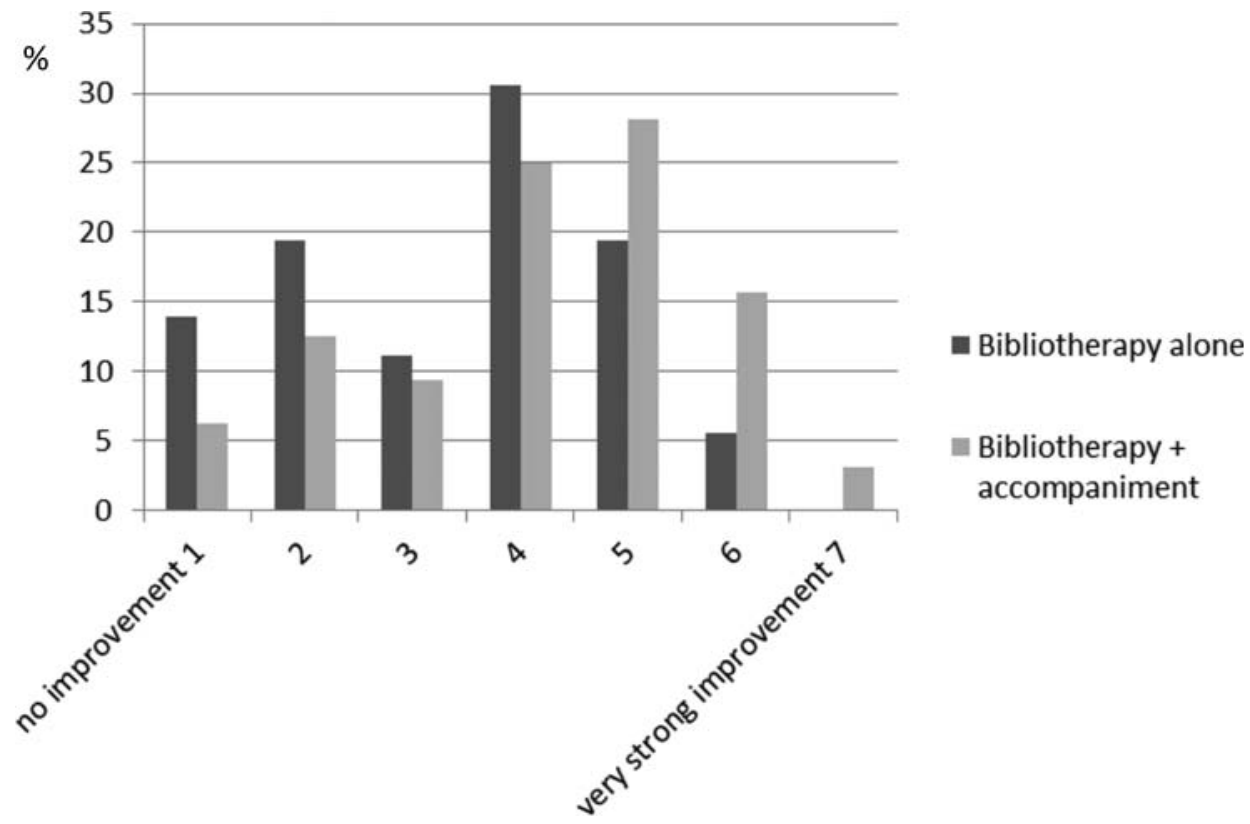

Figure 2. Self-reported improvement scores in pure self-treatment and guided self-treatment groups.

A significant difference was found between guided and pure self-treatment groups on improvement scores $(t=2.08, d f=65, p<.05)$, but not on the CGIC. Moreover, within the guided self-treatment group, participants who had two sessions with a study therapist $(n=14)$ reported better improvement than those who had only one $(n=13)$, with a mean score of $4.92( \pm 0.86)$ compared to $3.69( \pm 1.89)$ for the latter $(t=2.14, d f=24, p<.05)$.

\section{Multivariate analyses}

As shown in Table 4, MANOVAs revealed no significant effect of treatment-group interaction, which suggests that differences identified between pure and guided self-treatment groups may not be related to the specific effect of therapist support.

Table 5 indicates that treatments seem to have had similar effects for lifelong, acquired, and other forms of PE.

Table 4. Influence of guidance: repeated measures MANOVAs. Non-significant interaction effects call into question the hypothesis that guidance influenced treatment outcome.

\begin{tabular}{lccc}
\hline Dependent variables & $\begin{array}{c}\text { Treatment effect (baseline } \\
\text { vs. post-test) }\end{array}$ & $\begin{array}{c}\text { Group effect (pure vs. guided } \\
\text { self-treatment) }\end{array}$ & Interaction effect \\
\hline Self-reported IELT, control, distress & $F(4,65)=53.79$ & $F(4,65)=5.40$ & $F(4,65)=1.64$ \\
and satisfaction & $p<.001$ & $p<.001$ & $\mathrm{~ns}$ \\
PEP indexes & $F(5,64)=13.23$ & $F(5,64)=1.09$ & $F(5,64)=0.68$ \\
& $p<.001$ & $\mathrm{~ns}$ & $\mathrm{~ns}$ \\
SIQ scales & $F(5,62)=9.50$ & $F(5,62)=5.36$ & $F(5,62)=0.92$ \\
& $p<.001$ & $p<.001$ & $\mathrm{~ns}$ \\
\hline
\end{tabular}

F: Fisher's test. 
Table 5. Influence of subtypes: repeated measures MANOVAs. No differences were found between lifelong, acquired and other forms of PE.

\begin{tabular}{lccc}
\hline Dependent variables & $\begin{array}{c}\text { Treatment effect (baseline vs. } \\
\text { post-test) }\end{array}$ & $\begin{array}{c}\text { Group effect (PE } \\
\text { subtype) }\end{array}$ & $\begin{array}{c}\text { Interaction } \\
\text { effect }\end{array}$ \\
\hline $\begin{array}{l}\text { Self-reported IELT, control, distress and } \\
\text { satisfaction }\end{array}$ & $\begin{array}{c}F(4,63)=35.65 \\
p<.001\end{array}$ & $\begin{array}{c}F(8,126)=1.39 \\
\mathrm{~ns}\end{array}$ & $\begin{array}{c}F(8,126)=0.95 \\
\mathrm{~ns}\end{array}$ \\
PEP indexes & $\begin{array}{c}F(5,62)=10.75 \\
p<.001\end{array}$ & $\begin{array}{c}F(10,124)=1.41 \\
\mathrm{~ns}\end{array}$ & $\begin{array}{c}F(10,124)=1.20 \\
\mathrm{~ns}\end{array}$ \\
SIQ scales & $F(5,60)=6.83$ & $F(10,120)=1.27$ & $\begin{array}{c}F(10,120)=1.09 \\
\mathrm{~ns}\end{array}$ \\
\hline
\end{tabular}

F: Fisher's test.

\section{Other possible mediators of treatment outcome}

In the pure-self-treatment group, stepwise analyses found only sexual communication skills (SIQ-F2) to be a predictor of CGIC $\left(F=14.99, p<.01\right.$, adjusted $\left.R^{2}=0.37\right)$.

In the guided self-treatment group, stepwise regressions identified the WAI-bond subscale as the best predictor of CGIC $\left(F=30.83, p<.01\right.$, adjusted $\left.R^{2}=0.51\right)$, and the WAItotal scale as the best predictor of self-reported improvement $(F=16.35, p<.01$, adjusted $\left.R^{2}=0.34\right)$.

No other independent variables such as time lapse, socio-demographics or other baseline measures were significant in the regression models.

\section{Perception of the treatment}

Participants in the guided self-treatment group rated the bibliotherapy manual as more useful than those who had pure self-treatment $(M[\mathrm{sd}]=4.91[0.44]$ vs. $3.78[1.68], t=2.96$, $d f=66, p<.05)$. Within the guided self-treatment group, those who had two appointments with a therapist rated the manual as more useful than those who had only one $(M$ $[\mathrm{sd}]=5.62[0.77]$ vs. $4.38[1.56], t=2.56, d f=24, p<.02$ )

With regard to the statements: "Meeting a therapist allowed me to understand some topics I couldn't understand with bibliotherapy alone", "The meeting was useful", "The meeting allowed to adjust the treatment to my personal situation" and "The meeting was an important motivational support", participants gave mean scores of 3.97 ( $\mathrm{sd}=1.56$ ), 4.52 (1.59), 3.59 (1.59) and 4.13 (1.72), respectively, which corresponded to a rating of "moderately true".

Among these statements and the four WAI scores, only ratings of the usefulness of the meeting appeared to be significantly associated $(p<.05)$ with ratings of the usefulness of the bibliotherapy manual $(r=0.54)$.

\section{Discussion}

\section{Treatment effects}

The magnitude of the changes observed in the pure self-treatment condition was comparable to that previously reported by Kempeneers et al. (2012) using the same bibliotherapy manual. Replicating similar outcomes, the present study thus corroborated the usefulness this self-help approach for PE complaints. 
MANOVA failed to establish a significant effect of supplementing the manual with therapist support. However, it is difficult to conclude that the addition of brief guidance to bibliotherapy did not provide any benefit whatsoever. Indeed, some observations suggest the possibility that therapist support could modestly enhance the self-treatment outcomes: improvement on a greater number of outcomes measures was found when the manual was supplemented with brief therapist guidance. Participants in the assisted selftreatment group also reported higher feelings of improvement and rated higher the usefulness of the bibliotherapy.

Furthermore, improvement on some measures appeared to be related to the number of appointments with a study therapist. This suggests that the modest effect of therapist support might be partly attributable to the low level of therapist input, which was a maximum of 90 minutes in this study. Further improvements might therefore be obtained if this input was increased.

Another factor which may have reduced the benefit of therapist guidance was the limited professional experience of the therapists. The fact that over $90 \%$ of therapists were female may also have had an impact, and one could speculate as to whether the outcomes might have been different had the therapists been older and mostly male.

On the other hand, it should also be kept in mind that the treatment effects observed in this study might have reached a ceiling level, and that supplementing bibliotherapy with minimal or substantial therapist support might not greatly influence outcomes, just as some authors had found it in the field of anxiety and mood disorders at least (Den Boer, Wiersma, \& Van de Bosch 2004; Farrand \& Woodford, 2013). Further studies manipulating the extent of therapist input would be required to determine this matter.

It would be bold to suggest that 45-90 minutes of therapist contact could suffice to establish an authentic therapeutic alliance. Nevertheless, the links found in this study between the WAI scores and the indexes of improvement support the widespread idea that the perceived quality of a helping relationship is a major correlate of therapeutic change (Hill \& Knox, 2009; Martin et al., 2000; Smith \& Glass, 1977; Wampold, 2001).

With or without therapist support, this self-treatment led to similar outcomes in men with all subtypes of PE. This finding was unexpected, given other authors' proposals that CBT would not be effective for treating ISSM lifelong PE, and that long-term use of serotonergic agents would be the only viable treatment for men with this form of the disorder (Althof et al., 2010; Porst 2012; Waldinger, 2007). We fully acknowledge, along with these authors, that bio-constitutional factors play an important part in lifelong PE, favouring very short IELT. However, we should also recognize the obvious plasticity of the biological condition, which suggests that CBT can be an appropriate and effective intervention for these men also. Finally, in terms of penetration duration, cultural norms and expectations often appear to exceed the biological norms (Amidu, Owiredu, Dapare, \& Anuamwine, 2015; Burri, Giuliano, McMahon, \& Porst, 2014; Corty \& Guardiani, 2008; Miller \& Byers, 2004). As a result, legions of "biologically normal" men must learn how to control their excitement in order to prolong penetration beyond their natural limit. And many manage to do so, with or without the help of a sex therapist. The process may be similar for men with lifelong PEs, for men who present a priori very short penetration times. It could be more difficult for these men to learn new behaviours, but not impossible.

Improvements were reported on almost all measures of sexual functioning, in both pure and guided self-treatment groups. However, the improvements on measures of 
sexual satisfaction were quite modest, but this is not surprising, given that overall sexual satisfaction is likely to depend on several factors in addition to PE, unlike measures such as "feeling of control upon ejaculation" or "PE-related distress". This assumption is supported by reports from two experts committees, suggesting that sexual satisfaction is a poor marker for PE (McMahon et al., 2008; Serefoglu et al., 2014).

The analyses conducted did not identify many significant predictors of treatment outcome. Some participants endorsing less dysfunctional sexual beliefs, and specifically fewer beliefs impairing sexual communication, tended to report better improvement post-treatment. Neither educational level nor PE subtype predicted differences in treatment outcome. This finding is not consistent with previous research suggesting that bibliotherapy tends to be more effective for situational than for ISSM lifelong PE (Kempeneers et al., 2012). Rather, in agreement with Jannini and Lenzi's views (2013), it challenges the idea that algorithms could be developed to match subtypes of PE to specific interventions.

As in the study by Kempeneers et al. (2012), improvements in sexual functioning were accompanied by changes in sexual cognitions, supporting the idea that a significant component of the treatment involved cognitive change. Very little is known about cognitive risk factors in PE. This topic could be of interest for future research. For example, sexual communication skills measured at baseline in this study predicted higher self-reported change at post-treatment among men who used the pure self-treatment. Might this suggest that dysfunctional cognitions around sexual communication are an important component of PE problems and need to be addressed in sex therapy?

\section{Limitations of the present study}

As participants in this study may not be a representative sample of the population of men with PE, the findings should be interpreted with caution. For example, participants' educational level was rather high compared to the general population, possibly as a result of recruitment process, which necessitated exposure to specific media, as well as the ability and willingness to use a bibliotherapy intervention.

A small number of participants, especially in the acquired PE group, suggest that the finding of no differences across subtypes of PE should be interpreted with caution.

Finally, only $52.59 \%$ of participants completed the protocol. It is of course impossible to know exactly why some participants did not complete the post-treatment questionnaire, and very little is known about attrition in Internet-based studies. Nevertheless, one cannot rule out the possibility that lack of benefit from the treatment might have contributed to the drop-out rate, and that the treatment effect sizes might be somewhat inflated by the higher level of motivation of remaining participants.

\section{Conclusions}

The results from the study support the hypothesis that cognitive-behaviour self-treatment is an effective intervention for PE.

It cannot be regarded as certain that additional therapist support could lead to enhanced treatment effects, since the benefits of guided self-help compared to pure selfhelp were found to be non-significant or only modest. Nevertheless, the weakness of an 
additional guidance benefit might be due to the minimal amount of therapist support offered. In this case, outcomes might well be improved simply by increasing the amount of therapist input. On the other hand, there may well be a ceiling effect for therapist support, similar to that found in some studies of bibliotherapy for mood and anxiety disorders.

Improvements in sexual functioning were associated with changes in sexual cognitions, suggesting that these play a key role in $\mathrm{PE}$ and its treatment.

Improvements were found for all types of PE, suggesting that the cognitive and behavioural factors targeted in this intervention play a role across various forms of the disorder.

\section{Note}

1. The protocol was approved by the Ethics Committee of the Faculty of Psychology of the University of Liege (Belgium) on 11 July 2012.

\section{Acknowledgement}

This study was led in collaboration by the University of Liege (B), Departments of Psychology and Urology, and Province of Liege Department of Health and Quality of Life (B) .

\section{Disclosure statement}

No potential conflict of interest was reported by the authors.

\section{Notes on contributors}

Philippe Kempeneers, $M S, M A, P h D$, is a psychologist and sexologist. He teaches certificate specialization programs in clinical sexology at Universities of Liege, Brussels and Louvain. From 2009 to 2014, he led the BibliothEP project, a study evaluating the effectiveness of bibliotherapy for premature ejaculation, under the auspices of University and Province of Liege. He is past-president of the SSUB, the French-speaking Belgian society of sexology.

Robert Andrianne, $M D, P h D$, is senior urologist and professor of sexual medicine at the University of Liege.

Marion Cuddy, DClinPsy, PhD, is clinical psychologist based in London. She specialises in cognitive behaviour therapy for individual and couples, and is currently Secretary of the Couple Special Interest Group of the British Association for Cognitive and Behavioural Psychotherapies.

Isabelle Georis, BA, MS, is a sexologist and sex therapist in Liege.

Quentin Longrée, MS, is a clinical psychologist in Liege.

Sylvie Blairy, MS, PhD, is a clinical psychologist and professor at the University of Liege. She teaches cognitive behaviour therapies and the psychology of emotions. She is Chief editor of RFCCC, a French-speaking journal of cognitive and behavioural therapies. 


\section{References}

APA. (2000). DSM-IV-TR: Diagnostic and statistical classification of mental disorders (4th ed. Text Revision). Washington, DC: Author.

APA. (2013). DSM-5: Diagnostic and statistical classification of mental disorders (5th ed. Text Revision). Washington, DC: Author.

Althof, S. E., Abdo, C. H. N., Dean, J., Hacket, G., McCabe, M., McMahon, C. G., ... Tan, H. M. (2010). International Society for Sexual Medicine's guidelines for the diagnosis and treatment of premature ejaculation. Journal of Sexual Medicine, 7, 2947-2969.

Amidu, N., Owiredu, W. K. B. A., Dapare, P. P. M., \& Anuamwine, B. B. (2015). Perceptions of normal and abnormal ejaculatory latency times: An observational study in Ghanaian males and females. European Journal of Medical Research, 20, 75. doi: 10.1186/540001-015-0169-6.

Blanken, I., Leusink, P., van Diest, S., Gijs, L., \& van Lankveld, J. J. D. M. (2014). Outcome predictors of internet-based brief sex therapy for sexual dysfunctions in heterosexual men. Journal of Sex and Marital Therapy, 11, 1-13.

Burri, A., Giuliano, F., McMahon, C., \& Porst, H. (2014). Female partner's perception of premature ejaculation and its impact on relationship breakups, relationship quality, and sexual satisfaction? Journal of Sexual Medicine, 11, 2243-2255.

Carr, F., \& Sutter, P. (2001). Confidential file 101. New York, NY: Anglehart Press.

Corbière, M., Bisson, J., Lauzon, S., \& Ricard, N. (2006). Factorial validation of a French short-form of the working alliance inventory. International Journal of Methods in Psychiatric Research, 15, $36-45$.

Cormio, L., Massenio, P., La Rocca, R., Verze, P., Mirone, V., \& Carrieri, G. (2015). The combination of dapoxetine and behavioral treatment provides better results than dapoxetine alone in the management of patients with lifelong premature ejaculation. Journal of Sexual Medicine, 12, 1609-1615.

Corty, E. W., \& Guardiani, J. M. (2008). Canadian and American sex therapists' perceptions of normal and abnormal ejaculatory latencies: How long should intercourse last? Journal of Sexual Medicine, 5, 1251-1256.

De Carufel, F., \& Trudel, G. (2006). Effects of a new functional-sexological treatment for premature ejaculation. Journal of Sex and Marital Therapy, 32, 97-114.

De Sutter, P., Reynaert, N., Van Broeck, N., \& De Carufel, F. (2002). Treatment of premature ejaculation by a cognitivo-behavioral bibliotherapy. [Traitement de l'éjaculation précoce par une approche bibliothérapeutique cognitivo-comportentale sexologique]. Journal de Thérapie Comportementale et Cognitive, 12, 131-136.

Den Boer, P. C. A. M., Wiersma, D., \& Van de Bosch, R. J. (2004). Why is self-help neglected in the treatment of emotional disorders? A meta-analysis. Psychological Medicine, 34, 959-971.

Farrand, P., \& Woodford, J. (2013). Impact of support of written cognitive behavioural self-help: A systematic review and meta-analysis of randomised controlled trials. Clinical Psychology Review, $33,182-195$.

Guy, W. (1976). ECDEU assessment manual for psychopharmacology. Rockville, MD: U.S. Department of Health, Education and Welfare.

Hill, C. E., \& Knox, S. (2009). Processing the therapeutic relationship. Psychotherapy Research, 19, $13-29$.

Jannini, E., \& Lenzi, A. (2013). Pathophysiology of acquired premature ejaculation. In E. Jannini, C. G. McMahon, \& M. D. Waldinger (Eds.), Premature ejaculation. From etiology to diagnosis and treatment (pp. 81-97). Milan: Springer.

Jern, P. (2013). Evaluation of a behavioral treatment intervention for premature ejaculation using a handheld stimulating device. Journal of Sex and Marital Therapy, 40, 358-366.

Kaplan, H. S. (1989 ). PE: How to overcome premature ejaculation. New York, NY: Bruner/Mazel.

Kempeneers, P., Andrianne, R., Bauwens, S., Georis, I., Pairoux, J. F., \& Blairy, S. (2012). Clinical outcomes of a new self-help booklet for premature ejaculation. Journal of Sexual Medicine, 9, 2419-2428. 
Kempeneers, P., Louwette, S., Mormont, C., \& Doudali, P. (2000). French adaptation and validation of McCormick and Jordan's sexual irrationality questionnaire. [Adaptation et validation française du Sexual Irrationality Questionnaire (SIQ) de McCormick et Jordan]. Revue Francophone de Clinique Comportementale et Cognitive, 5, 5-18.

Kempeneers P., Bauwens S., \& Andrianne R. (2015). Fighting against premature ejaculation: A practical guide [ Lutter contre l'éjaculation précoce : guide pratique]. Paris: De Boeck-Solal.

Martin, D. J., Garske, J. P., \& Davis, M. K. (2000). Relation of therapeutic alliance with outcome and other variables: A meta-analytic review. Journal of Consulting and Clinical Psychology, 68, 438450.

Masters, W. H., \& Johnson, V. E. (1970). Human sexual inadequacy. Boston, MA: Little, Brown.

McCormick, N. B., \& Jordan, T. J. (1986). Thoughts that destroy intimacy: Irrational beliefs about relationships and sexuality. In W. Dryden \& P. Tower (Eds.), Rational-emotive therapy: Recent developments in theory and practice (pp. 47-62). Bristol: Institute for RET.

McMahon, C. G., Althof, S. E., Waldinger, M. D., Porst, H., Dean, J., Sharlip, I. D., ... Segraves, R. (2008). An evidence-based definition of lifelong premature ejaculation: Report of the International Society for Sexual Medicine (ISSM) ad hoc committee for the definition of premature ejaculation. Journal of Sexual Medicine, 5, 1590-1606.

Metz, M. E., \& McCarthy, B. W. (2003). Coping with premature ejaculation. Oakland, CA: New Harbinger Publications.

Miller, S. A., \& Byers, E. S. (2004). Actual and desired duration of foreplay and intercourse: Discordance and misperceptions within heterosexual couples. The Journal of Sex Research, 41, 301309.

Patrick, D. L., Giuliano, F., Ho, K. F., Gagnon, D. D., McNuly, P., \& Rothman, M. (2008). The premature ejaculation profile: Validation of self-reported outcome measures for research and practice. British Journal of Urology, International, 103, 358-367.

Porst, H. (2012). Premature ejaculation. In H. Porst, Y. Reisman (Eds.), The European Society of Sexual Medicine syllabus of sexual medicine (pp. 547-592). Amsterdam (NL): Medix Publishers.

Serefoglu, E. C., McMahon, C. G., Waldinger, M. D., Althof, S. E., Shindel, A., Adaikan, G., ... Torres, L. O. (2014). An evidence-based unified definition of lifelong and acquired premature ejaculation: Report of the second International Society for Sexual Medicine ad hoc committee for the definition of premature ejaculation. Journal of Sexual Medicine, 11, 1423-1441.

Smith, M. L., \& Glass, G. V. (1977). Meta-analysis of psychotherapy outcome studies. American Psychologist, 32, 752-760.

Trudel, G., \& Proulx, S. (1987). Treatment of premature ejaculation by bibliotherapy: An experimental study. Journal of Sex and Marital Therapy, 2, 163-167.

Waldinger, M. D. (2007). Premature ejaculation: Definition and drug treatment. Drugs, 67, 547568.

Waldinger, M. D. (2013). Pathophysiology of lifelong premature ejaculation. In E. Jannini,C. G. McMahon \& M. D. Waldinger (Ed.), Premature ejaculation. From etiology to diagnosis and treatment (pp. 71-80). Milan: Springer.

Wampold, B. (2001). The great psychotherapy debate. Nahwah, NJ: Lawrence Erlbaum.

Zeiss, R. A. (1978). Self-directed treatment for premature ejaculation. Journal of Consulting and Clinical Psychology, 46(6), 1234-1241.

Zeiss, R. A., \& Zeiss, A. (1978). Prolong your pleasure. New York, NY: Pocket Books. 